\title{
Ankylosing spondylitis with predominant involvement of the cervical spine in a woman with Behçet's syndrome
}

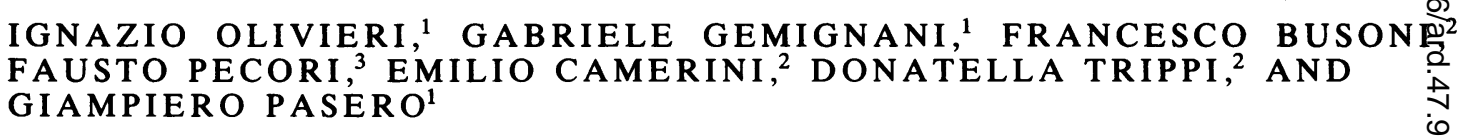

From the ${ }^{1}$ Rheumatic Disease Unit of the Institute of Medical Pathology 1, University of Pisa; the ${ }^{2}$ Institute Radiology, University of Pisa; and the ${ }^{3}$ Blood Transfusion Service, 'Santa Chiara' Hospital, Pisa, ItaR

SUMmaRY The case of a 45 year old woman affected by both Behçet's syndrome (BS) awd ankylosing spondylitis (AS) is reported. Cervical spine involvement was observed long before t appearance of the sacroiliac and lumbar changes.

Key words: sacroiliitis, seronegative spondarthritides, computed tomography.

Roentgenographic evidence of sacroiliitis is an indispensable condition for the diagnosis of ankylosing spondylitis (AS). ${ }^{1}$ Nevertheless, cases with spinal features typical of AS and normal sacroiliac joints have also been reported. ${ }^{2-4}$

Cervical changes are not infrequent in patients with AS. ${ }^{6}$ These tend to occur later than thoracic and lumbar features and are more prevalent in women. ${ }^{56}$ Abnormalities in the cervical spine and sacroiliac joints, with sparing of the thoracic and lumbar segments, are also relatively more prevalent in women. 6

The inclusion of Behçet's syndrome (BS) among the seronegative spondarthritides is under consideration. ${ }^{7-11}$ Some investigators have reported an increased prevalence of sacroiliitis and AS in patients with $\mathrm{BS},{ }^{8}$ but others have found a prevalence that does not differ from that of the general population. ${ }^{9-11}$

The case described here illustrates the unusual course of AS, involving predominantly the cervical spine, in a woman with BS. Only recently have lumbar spine and sacroiliac joint features become evident.

Accepted for publication 25 November 1987.

Correspondence to Dr Ignazio Olivieri, Istituto di Patologia Medica 1, Servizio di Reumatologia, Via Roma 2, 56100 Pisa, Italy.

\section{Case report}

A 45 year old woman was referred to the rheumat disease unit in June 1984 after suffering for two years from neck pain and decreasing range of movement of the cervical spine. The pain was more prominent in the early morning and was relieved ofy exercise.

Her medical history included episodic inflamm tory low back pain and stiffness in the previous 20 years, four episodes of disseminated painful orăl ulceration, one episode of erythema nodosum, and numerous episodes of disseminated papulopustular skin lesions in the previous 10 years. She denied arti history of psoriasis, urethritis, conjunctivitis? peripheral arthritis, gastrointestinal, neurological or cardiovascular symptoms.

Her family history was negative for seronegative spondarthritides, BS, or idiopathic recurrem aphthous stomatitis.

Physical examination showed a severe restriction of movement of the cervical spine in all directions. Extension, flexion (modified Shober test $19.5 \mathrm{~cm}$, and lateral bending of the lumbar spine were slightify limited. Chest expansion was $4 \mathrm{~cm}$. The skin prick test (pathergy test) was negative.

The only aspect of laboratory evaluation worth 
of note was the erythrocyte sedimentation rate of 30 $\mathrm{mm} / 1 \mathrm{st} h$ (Westergren). HLA typing was positive for $\mathrm{A} 2, \mathrm{~A} 3, \mathrm{Bw} 51$, and $\mathrm{B} 12$ antigens.

Cervical spine radiography showed anterior syndesmophytic bridging extending from $\mathrm{C} 4$ to $\mathrm{C} 6$, reduction in height of the C6-7 intervertebral disc, and narrowing, irregularity, and sclerosis of the apophyseal joints, all characteristic features of AS (Fig.1). Radiographs of the sacroiliac joints and the thoracic and lumbar spine were normal.

During the last three years the patient had recurrent episodes of disseminated papulopustular skin lesions on the trunk and upper and lower limbs, and recurrent episodes of painful genital and buccal aphthous ulceration. The pathergy test was persistently negative.

During the last 18 months her inflammatory low back pain was persistent and unresponsive to non-steroidal anti-inflammatory drugs, including

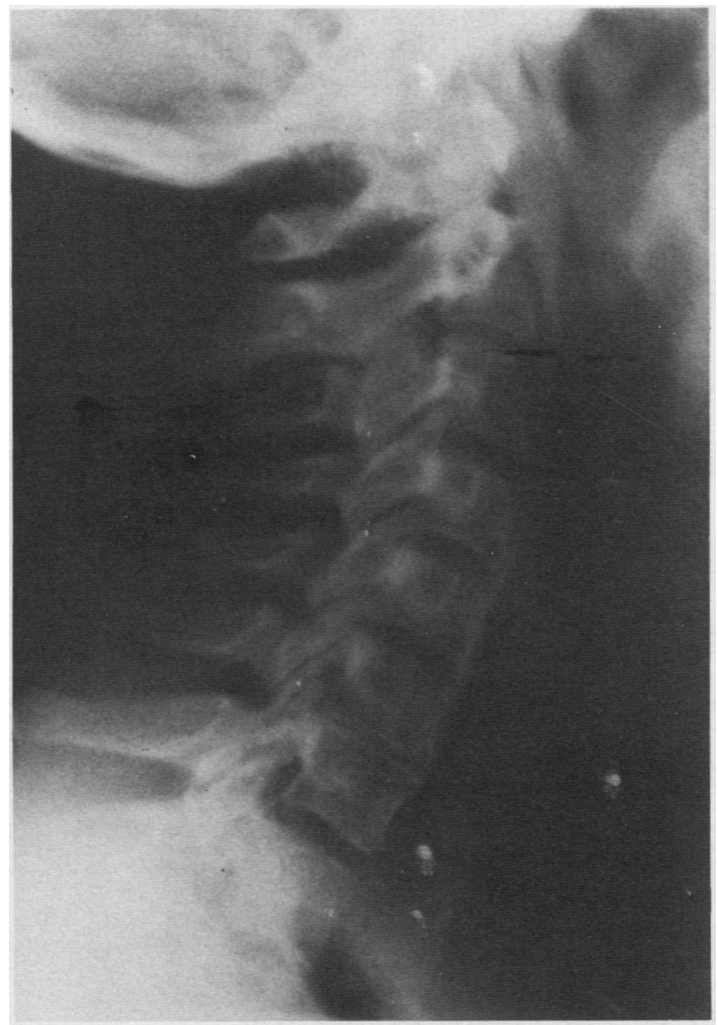

Fig. 1 Lateral radiograph of the cervical spine, taken in June 1984, showing syndesmophytes extending from C4 to C6, apophyseal joint sclerosis, irregularity, and narrowing, together with a reduction in height of the C6-7 intervertebral disc.

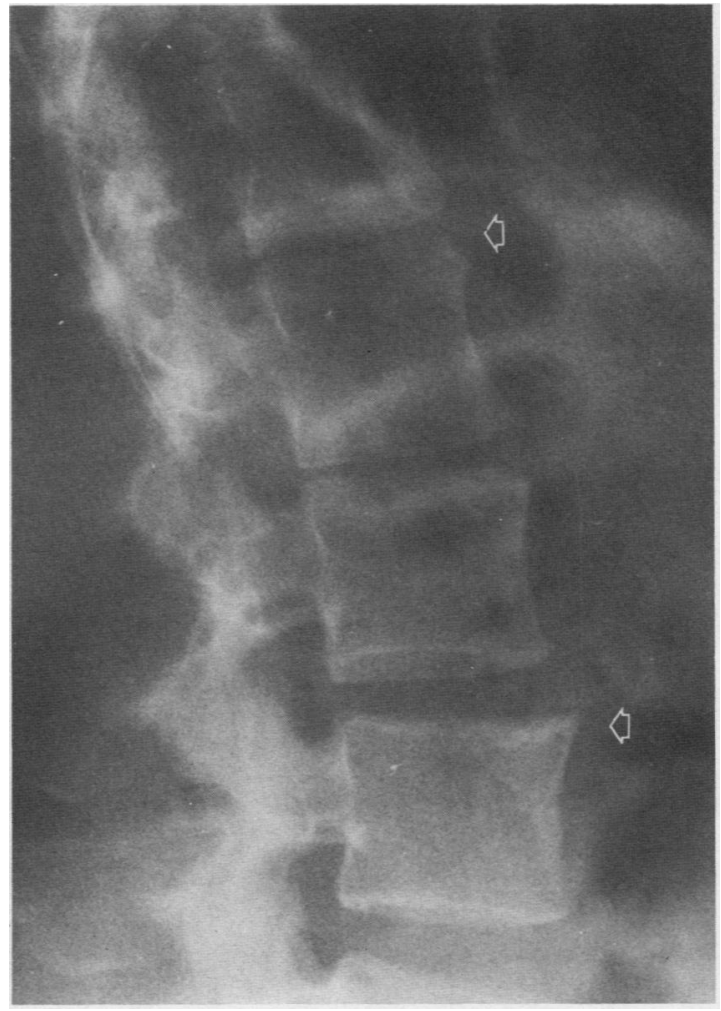

Fig. 2 Lateral radiograph of the lumbar spine, taken in November 1986, showing erosion surrounded by sclerosis ('Romanus lesion') of the upper corner of the second lumbar vertebra and proliferative spur of new bone of the fourth.

phenylbutazone. Movement of the lumbar spine decreased despite physical treatment. In June 1987 the modified Shober test gave a result of $18.5 \mathrm{~cm}$. Chest expansion had decreased to $2.5 \mathrm{~cm}$.

Radiological examination in November 1986 showed subchondral osteitis of the upper corner of the second and fourth lumbar vertebrae (Fig. 2), typical of AS, as well as an evolution of the features in the cervical spine (Fig. 3). The sacroiliac joints showed a mild sclerosis (Fig. 4a). Computed tomography, performed at that time, showed sclerosis and a slight irregularity in the left sacroiliac joint and severe sclerosis and erosions in the right joint (Fig. 4b).

\section{Discussion}

Our patient meets the diagnostic criteria for BS as suggested by Mason and Barnes, ${ }^{10}$ O'Duffy, ${ }^{12}$ and 


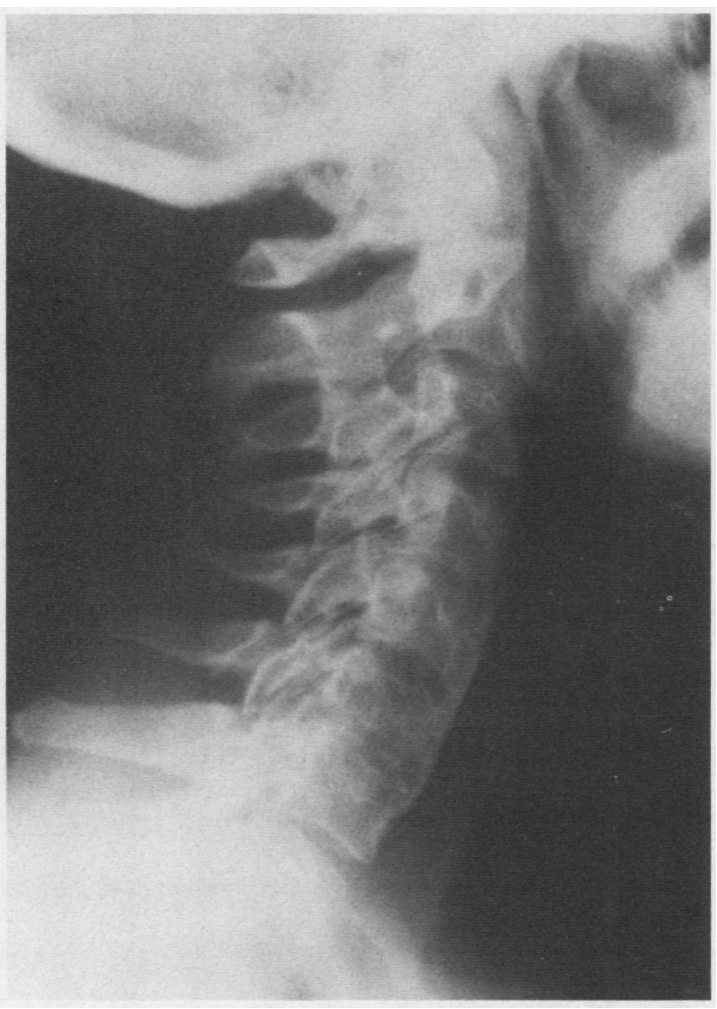

Fig. 3 Lateral view of the cervical spine, obtained in November 1986, illustrating the evolution of the features shown in Fig. 1.

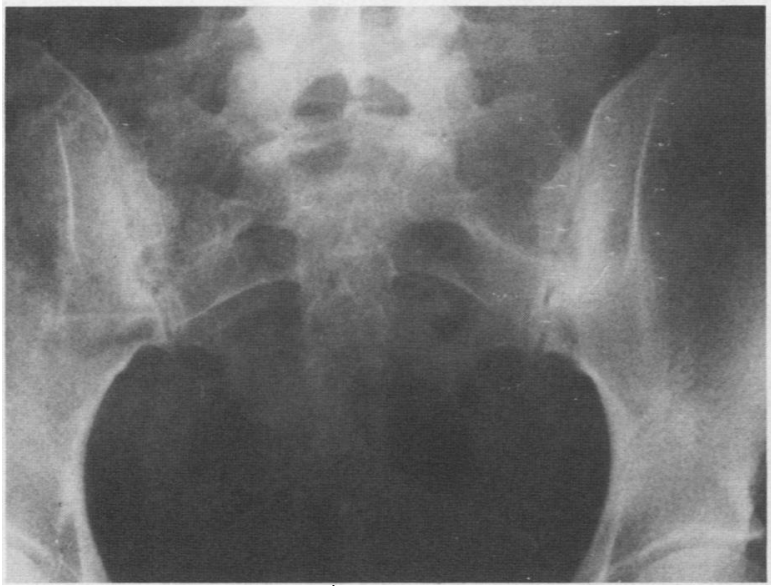

Fig. $4 \mathrm{a}$ the Japanese Committee on BS. ${ }^{13}$ She is positive for the HLA-B5 antigen (Bw51 split), which has been found to be associated with BS in Japanese, ${ }^{14}$ Turkish, ${ }^{15}$ and other Middle Eastern and Mediterranean populations, including Italians. ${ }^{16}$ No significant association has been observed in English ${ }^{17}$ or North American Caucasoid patients. ${ }^{18}$ According to Lehner and Batchelor only eye involvement is associated with the HLA-B5 antigen in English patients, whereas mucocutaneous involvement is associated with HLA-B12. ${ }^{17}$ Our patient has a 'mucocutaneous type' of BS and is positive for HLA-B12.

Our patient also meets the New York criteria for AS. ${ }^{1}$ When we first saw the patient in 1984 she had radiological features typical of AS only in her cervical spine. The lumbar and the sacroiliac joints were normal. Although it was possible to exclude the other conditions that can cause cervical spine ossification and hyperostosis, ${ }^{19}$ we were reluctant to diagnose seronegative spondarthropathy. Radiological follow up has shown the appearance of typical features of AS in the lumbar spine and equivocal findings in the sacroiliac joints. Sacroiliac changes were better shown by computed tomography, which has been found to be useful in the early diagnosis of sacroiliitis. ${ }^{20}$

The inclusion of BS among the seronegative spondarthritides is still being debated. ${ }^{7-11}$ Dilşen $e t$ al have recently re-evaluated 331 Turkish patients with BS for sacroiliitis and $\mathrm{AS}^{8}$ Thirty three patients $(10 \%)$ were found to have AS and 112

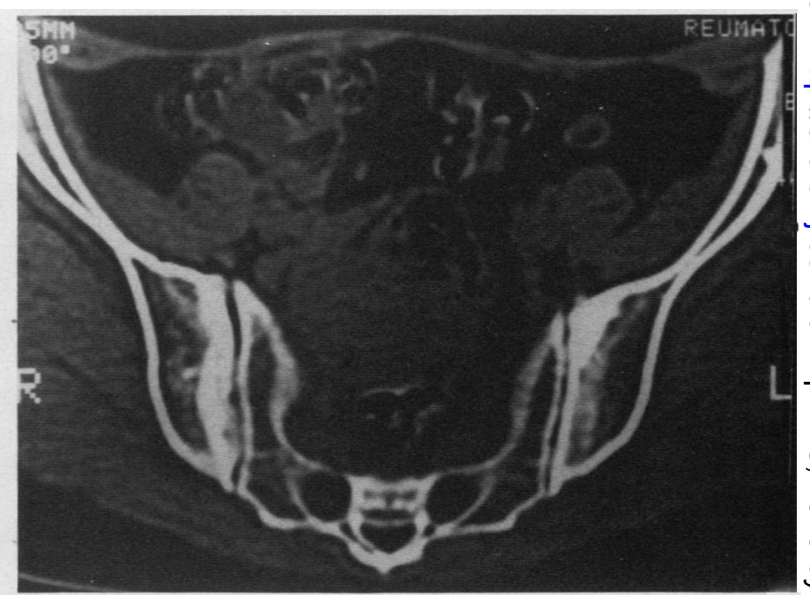

Fig. 4b

Fig. 4 (a) Conventional radiograph of the sacroiliac joints, taken in November 1986, showing sclerosis in both joints. (b) Computed tomography ihrough the synovial portion of the sacroiliac joints, obtained at the same time, showing severe sclerosis, and narrowing and erosions of the right sacroiliac joint. The left joint shows a milder sclerosis and irregularity of the joint space. 
(34\%) sacroiliitis. None of the 92 controls had AS and only $5(5 \%)$ had sacroiliitis. Patients with both AS and BS had a significantly higher incidence of both the HLA-B5 and HLA-B27 antigens than controls. Other authors have reported that there is no association between BS and AS. ${ }^{9-11}$ Surprisingly, Yazici et al did not find any increase in the prevalence of sacroiliitis, in comparison with controls, in their Turkish series of BS. ${ }^{9}$ Only one of their 184 patients with BS presented definite AS. They have recently suggested that high observer variation' in interpreting the conventional anteroposterior view of the sacroiliac joints may account for the reported association between BS and sacroiliitis. ${ }^{21}$

A single case, of course, does not permit us to take sides in the controversy. We wish to emphasise, however, that, if BS and AS are really associated diseases, then secondary AS can begin in the spinal column rather than in the sacroiliac joints and may affect the cervical segment earlier and more severely than the lumbar one, as sometimes happens in primary AS, especially in women.

\section{References}

1 Bennet P H, Wood P H N. Population studies of the rheumatic diseases. Proceedings of the Third International Symposium, New York, 1966. Amsterdam: Excerpta Medica, 1968; 456-7.

2 Polley H F, Slocumb C H. Rheumatoid spondylitis: a study of 1035 cases. Ann Intern Med 1947; 26: 240-9.

3 Cheatum D E. 'Ankylosing spondylitis' without sacroiliitis in a woman without the HLA B27 antigen. J Rheumatol 1976; 3: $420-5$.

4 Calin A. Ankylosing spondylitis sine sacroiliitis. Arthritis Rheum 1979; 22: 303-4.

5 McEwen C, DiTata D, Lingg C, Porini A, Good A, Rankin T. Ankylosing spondylitis and spondylitis accompanying ulcerative colitis, regional enteritis, psoriasis and Reiter's disease. Arthritis Rheum 1971; 14: 291-318.

6 Resnick D, Dwosh I L, Georgen T G, et al. Clinical and radiographic abnormalities in ankylosing spondylitis: a comparison of men and women. Radiology 1976; 119: 293-8.

7 Moll J M H, Haslock I, Wright V. Seronegative spondarthritides. In: Scott J T, ed. Copeman's textbook of the rheumatic diseases. Edinburgh, London, Melbourne, New York: Churchill Livingstone, 1986: 723-44.

8 Dilşen N, Koniçe M, Aral O. Why Behçet's disease should be accepted as a seronegative arthritis. In: Lehner T, Barnes C G, eds. Recent advances in Behçet's disease. London, New York: Royal Society of Medicine Services, 1986: 281-4. (International Congress and Symposium Series No 103.)

9 Yazici H, Tuzlaci M, Yurdakul S. A controlled survey of sacroiliitis in Behçet's disease. Ann Rheum Dis 1981; 40: 558-9.

10 Mason R M, Barnes C G. Behçet's syndrome with arthritis. Ann Rheum Dis 1969; 28: 95-103.

11 Chamberlain M A. Behçet's syndrome in 32 patients in Yorkshire. Ann Rheum Dis 1977; 36: 491-9.

12 O'Duffy J D. Suggested criteria for diagnosis of Behçet's disease [Abstract]. Journal of Rheumatology. Supplement 1974; 1: 18.

13 Behçet's Disease Research Committee of Japan. Behçet's disease: guide to diagnosis. Jpn J Ophthalmol 1974; 18: 291-4.

14 Ohno S, Ohguchi M, Hirose S, Matsuda H, Wakisaka A, Aizawa M. Close association of HLA-Bw51 with Behçet's disease. Arch Ophthalmol 1982; 100: 1455-8.

15 Yazici H, Chamberlain M A, Schreuder I, D'Amari J, Müftüoğlu M. HLA antigens in Behçet's disease: a reappraisal by a comparative study of Turkish and British patients. Ann Rheum Dis 1980; 39: 344-8.

16 Adorno D, Pivetti Pezzi P, Bonini S, Masala C, Amendolea M A, Casciani C U. HLA-B5 and Behçet's disease. Tissue Antigens 1979; 14: 444-8.

17 Lehner T, Batchelor J R. Classification and an immunogenetic basis of Behçet's syndrome. In: Lehner T, Barnes C G, eds. Behçet's syndrome. London: Academic Press, 1979: 13-32.

18 O'Duffy J D, Taswell H F, Elveback L R. HL-A antigens in Behçet's disease. J Rheumatol 1976; 3: 1-3.

19 Resnick D. Hyperostosis and ossification in the cervical spine. Arthritis Rheum 1984: 27: 564-9.

20 Kozin F, Carrera G F, Ryan L M, Foley D, Lawson T. Computed tomography in the diagnosis of sacroiliitis. Arthritis Rheum 1981; 24: 1479-85.

21 Yazici $H$, Turunç $M$, Özdogăn $H$, Yurdakul S, Akinci A, Barnes C G. Observer variation in grading sacroiliac radiographs might be a cause of 'sacroilitis' reported in certain disease states. Ann Rheum Dis 1987; 46: 139-45. 